\title{
Research on the coordinated development of Beijing-Tianjin-Hebei and the upgrading path of manufacturing industry
}

\author{
XIA Dang ${ }^{1, a}$ \\ ${ }^{1}$ School of Economics and Management, Beijing Jiao Tong University, China, 100044 \\ a349146974@qq.com
}

Keywords: NVC, Coordinated Development, Manufacture, Upgrading Path

\begin{abstract}
With the coordinated development of Beijing, Tianjin and Hebei as a national strategy, the problem of coordinated development of regional economy has been paid more and more attention. As a pillar industry of the national economy, manufacturing industry has become one of the key points of industrial transformation and upgrading. Under the condition of open economy, the research on the coordinated development of regional economy and industrial restructuring and upgrading, cannot do without inspection, to upgrade the value chain. Therefore, research on Beijing-Tianjin-Hebei's upgrading of the manufacturing industry in the global value chain system is the key issue to be solved.
\end{abstract}

\section{Introduction}

With the coordinated development of Beijing, Tianjin and Hebei as a national strategy, the problem of coordinated development of regional economy has been paid more and more attention. As a pillar industry of the national economy, manufacturing industry has become one of the key points of industrial transformation and upgrading. Under the condition of open economy, the research on the coordinated development of regional economy and industrial restructuring and upgrading, cannot do without inspection, to upgrade the value chain. In the next few years, with the continuous deepening of opening policy and the continuous development of regional synergies, in the background of the global value chain (GVC), the regional development task of Beijing-Tianjin-Hebei region is inseparable from the industrial upgrading of the whole region, but at present, there is little research on the upgrading of traditional manufacturing industry in Beijing-Tianjin-Hebei in combination with regional synergetic development, industrial division of labor and dynamic construction of value chain.

\section{Problem Statement}

In June 2014, Beijing-Tianjin-Hebei coordinated development has become the national strategy, which is another regional coordinated development strategy following the Yangtze River Delta Economic Zone and the Pearl River Delta Economic Zone. April 30, 2015, the CPC Central Committee Political Bureau meeting considered and adopted the "Beijing-Tianjin-Hebei coordinated development plan", marking the top design of Beijing-Tianjin-Hebei coordinated development is basically completed. The outline pointed out that the promotion of Beijing-Tianjin-Hebei coordinated development is a major national strategy, its core is an orderly ease Beijing non-capital function, to achieve a breakthrough in Beijing-Tianjin-Hebei traffic integration, ecological environment protection, industrial transformation and upgrading and other key areas. This means that industrial upgrading and transfer in the context of synergistic development of regional economies will be one of the main points of implementation of this major national strategy, and the manufacturing industry as a pillar industry is the top priority of industrial upgrading and transfer: China's economic development shift is not stalled, and promote the industrial structure to the high-end forward, focus, difficulties and way out in the transformation of the manufacturing industry to upgrade. In 2016, the Beijing-Tianjin-Hebei national economic and 
social development "thirteen five" plan released, followed by the introduction of the Beijing-Tianjin-Hebei transportation, ecology, industry and other 12 special planning and a series of policy advice, formed a consistent goal, Mutual convergence of the coordinated development planning system.

Beijing-Tianjin-Hebei, covering two municipalities-Beijing, Tianjin, and Hebei Province, there are more than 100 million people living here and more than 1/10 of GDP ratio in the country. However, in the view of the domestic regional industry development status, Beijing-Tianjin-Hebei's economic development is very uneven, which distributed like a ladder, as shown in table 2.1.

Tab.2.1 The present status of economic development in Beijing-Tianjin-Hebei

\begin{tabular}{lccc}
\hline & $\begin{array}{c}\text { Per capita GDP } \\
\text { (yuan) }\end{array}$ & $\begin{array}{c}\text { Proportion of the } \\
\text { tertiary industry }\end{array}$ & $\begin{array}{c}\text { Urbanization } \\
\text { rate }\end{array}$ \\
\hline Beijing & 114717 & $80.3 \%$ & $86.50 \%$ \\
Tianjin & 115617 & $54.0 \%$ & $82.93 \%$ \\
Hebei & 42866 & $41.7 \%$ & $53.32 \%$ \\
\hline
\end{tabular}

Source: National Bureau of Statistics, the author calculated.

In the view of per capita GDP, Beijing and Tianjin's per capita GDP are more than 16,000 US dollars in 2016, while Hebei is only 6200 US dollars, less than $50 \%$ of Beijing and Tianjin; from the view of industrial structure, Beijing mainly on the tertiary industry, which accounting for $80.3 \%$, showing a clear trend of high-end, Tianjin's secondary industry accounted for $44.8 \%$, Hebei's secondary industry accounted for $47.3 \%$, the portion of Hebei and Tianjin's secondary industry accounted for nearly half; From the view of the urbanization rate, The urbanization rates of Beijing, Tianjin and Hebei were 86.4\%, 82.93\% and 53.32\% respectively. Comprehensive judgment, Beijing has entered the post-industrial stage, Tianjin in the late stages of industrialization, and Hebei is still in the middle stage of industrialization. With the disequilibrium development and the weak effects of Beijing as the core of the regional economic, the polarization effect of Beijing restrains the development of Hebei, leading to the surrounding areas of Beijing is lagging behind, which in turn restricts the relief of Beijing's non-capital functions.

Similar to the global value chain, the national value chain also includes three links, namely, technical aspects, production processes and marketing links. The added value of each link is different. Technical aspects include R\&D, design, etc; production processes include manufacturing, processing and assembly, quality inspection and inventory management; marketing links include sales, brand and after-sales service. figure 2.1 shows the added value of these links and the location in the GVC.

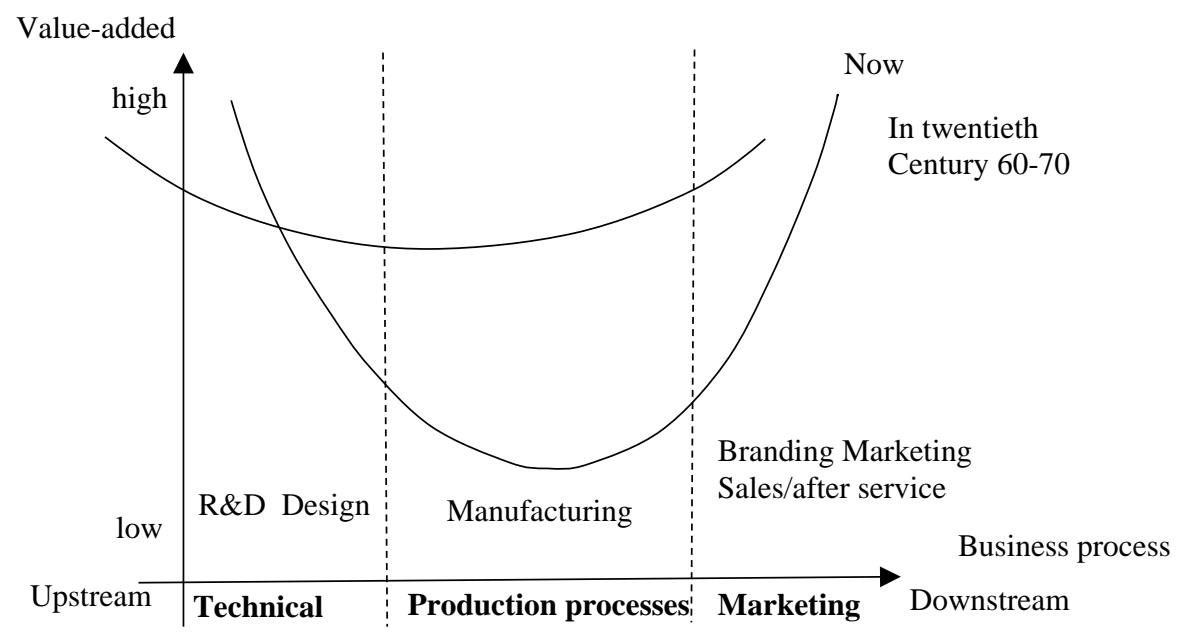

Fig.2.1 Smile curve under NVC

As can be seen from Figure 2.1, the technical links and marketing links were in the upstream and downstream positions in the GVC, both of which have a higher value-added level, and the 
production link is located in the middle of the smile curve having lower value added.

At present, China's traditional manufacturing industry belongs to low-end processing and manufacturing in the international division of labor, and multinational companies mastered the core technology and market channels are the controllers of global production layout and distribution of benefits. At the same time, other sub-suppliers in the industrial chain also rely on "waterfall effect" for industrial integration, leading to a high degree of concentration of industry. In addition, China's traditional manufacturing industry is facing the multiple control of leading manufacturers and sub-suppliers, increased the difficulty of catching up. With the loss of the traditional comparative advantage, coupled with the serious competition between homogeneous industries in Beijing-Tianjin-Hebei, the traditional manufacturing industry's upgrading situation in this region in value chain is not optimistic. How to break the low-end lock-in situation of Beijing-Tianjin-Hebei's manufacturing industry, how to find a new path of industrial (especially manufacturing) upgrade in the national strategy of Beijing-Tianjin-Hebei coordinated development is the key problem that needs to be solved urgently.

\section{Literature review}

Currently, an important background of China's economy is the increasing demand for the coordinated development of regional economy. Based on the theory of growth pole, the development of urban agglomeration based on core cities is increasingly leading the new pattern of the development of the current economic zone, and has been the main mode of regional competition. At the same time, regional industrial upgrading has broken through the regional boundaries in the context of GVC, and is closely integrated with territorialism and social backgrounds, so the characteristics of the region have an important impact on industrial upgrading. From the above we know that the industrial upgrading under the national value chain should be included in the framework of the coordinated development of regional economy.

2017 is the third year of the implementation of the "Beijing-Tianjin-Hebei Coordinated Development" program. Under the relevant projects and policies, the plan has made tangible progress. The co-ordination system of Beijing-Tianjin-Hebei is relatively mature. However, in recent years, Beijing-Tianjin-Hebei region's economic growth has been declining, of which in 2014-2016, Beijing and Tianjin's economic growth were declining, Hebei's growth rate even lower than the national economic growth in 2014 and 2015. Beijing-Tianjin-Hebei and the Yangtze River Delta, the Pearl River Delta's economic gap is also widening (see table 3.1).

Table 3.1 GDP growth in the three regions of 2014-2016

\begin{tabular}{|c|c|c|c|c|c|c|c|c|c|c|}
\hline & & \multicolumn{3}{|c|}{$\begin{array}{c}\text { Regional GDP (100 million } \\
\text { yuan) }\end{array}$} & \multicolumn{3}{|c|}{ Actual growth rate (\%) } & \multicolumn{3}{|c|}{$\begin{array}{l}\text { Percentage of the } \\
\text { country (\%) }\end{array}$} \\
\hline & & 2014 & 2015 & 2016 & $\begin{array}{l}2014 \\
2016\end{array}$ & & 2015 & $\begin{array}{l}2014 \\
2016 \\
\end{array}$ & & 2015 \\
\hline area & $\begin{array}{l}\text { entire } \\
\text { country }\end{array}$ & $\begin{array}{c}64397 \\
4 \\
\end{array}$ & $\begin{array}{c}68550 \\
6 \\
\end{array}$ & 744127 & 7.4 & 6.9 & 6.7 & 100 & 100 & 100 \\
\hline \multirow{3}{*}{$\begin{array}{l}\text { Beijing- } \\
\text { Tianjin- } \\
\text { Hebei }\end{array}$} & Beijing & 21330 & 22968 & 24899 & 7.3 & 6.9 & 6.7 & 3.12 & 3.17 & 3.35 \\
\hline & Tianjin & 15726 & 16538 & 17800 & 10 & 9.3 & 8 & 2.3 & 2.29 & 2.39 \\
\hline & Hebei & 29421 & 29806 & 31827 & 6.5 & 6.8 & 6.8 & 4.3 & 4.12 & 4.28 \\
\hline \multirow{4}{*}{$\begin{array}{l}\text { Yangtze } \\
\text { River } \\
\text { Delta }\end{array}$} & $\begin{array}{l}\text { Shangha } \\
\text { i }\end{array}$ & 23567 & 24964 & 27466 & 7.0 & 6.9 & 6.8 & 3.44 & 3.45 & 3.69 \\
\hline & Jiangsu & 65088 & 70116 & 76086 & 8.7 & 8.5 & 7.8 & 9.51 & 9.69 & 10.22 \\
\hline & Zhejiang & 40173 & 42886 & 46484 & 7.6 & 8.0 & 7.5 & 5.87 & 5.93 & 6.25 \\
\hline & Anhui & 20848 & 22005 & 24117 & 9.2 & 8.7 & 8.7 & 3.05 & 3.04 & 3.24 \\
\hline
\end{tabular}

Source: China Statistical Yearbook 2015-2017, the author calculated. 
The reasons for this phenomenon are that, on the one hand, the concept of the "Beijing-Tianjin-Hebei Coordinated Development" proposed relatively late, which caused the closely degree of Beijing-Tianjin-Hebei coordinated development is not as good as the Yangtze River Delta, coupled with the existence of different levels of similar industrial structure, scattered use of resources and regional vicious competition, restraining the development of regional comparative advantage, leading to the lack of impetus to industrial upgrading; on the other hand, with the development of economic globalization, the division of labor increasingly deepening, global industry continue to undergo gradient shifts, A large number of labor-intensive industries and the low-value link gradually shifted, and most developing countries are limited by their own backward industrial competitiveness and urgent industrial upgrading tasks, making the regional economic cooperation and industrial upgrading presents a new feature, the regional Competition is also increasingly reflected in industrial competition (Chen Jingya, 2013), at the same time, most areas of our country has entered the middle and late stage of industrialization, economic growth rate began to slow down, it is difficult to achieve real industrial technological progress and economic growth, through the introduction of high-end technology and equipment in developed countries and undertake international industrial transfer. Progress and economic growth will be more dependent on changing Embed way and regional industry linkage to promote industrial growth and value chain upgrading (Huang Qun Hui, 2014). As the traditional industrial-intensive zone, the comparative advantage of industrial development in Beijing-Tianjin-Hebei is obvious, but the overall economic strength of the Beijing-Tianjin-Hebei $r$ is weak compared with the Yangtze River Delta and the Pearl River Delta region, and the industrial structure is developed unbalanced., Along with the loss of traditional comparative advantage, the upgrading of value chain of Beijing-Tianjin-Hebei is not optimistic in the context of the GVC (Chen Jingya, 2013). The grim reality proves that economic catching can not be based on the comparative advantage of resources and labor, and must be based on dynamic technological change and industrial upgrading (Tuyingqing, 2011).

In the next few years, with the continuous deepening of the country's opening strategy and development of regional synergies, Beijing-Tianjin-Hebei regional development tasks can not be separated from the overall regional industrial upgrading in the GVC background. However, the existing research on the upgrading path of regional traditional manufacturing industry is either focused on the upgrade path of GVC (Tuyingqing, 2010; Chen Jingya, 2013; Liu Yurong, 2015; Liu Shiguo, Wu Haiying, 2015), or focused on the traditional manufacturing industry developed better in Yangtze River Delta, from the perspective of building a national value chain to explore the upgrading of manufacturing path. (Liu zhibiao, Yu Mingchao, 2009; Liu Zhibiao, Zhang Jie, 2009; Yue Zhonggang, Liu Zhibiao, 2011; Zhang Shaojun, Liu Zhibiao, 2013; Liu et al., 2014).). There is little research combined with regional synergistic development, industrial collaboration division of labor, value chain dynamic construction and other characteristics to discuss the upgrading path of Beijing-Tianjin-Hebei's traditional manufacturing. Although some people from the perspective of industrial value chain (IVC) to study the Beijing-Tianjin-Hebei manufacturing industry collaborative innovation and industrial upgrading (Such as Wu Yuying et al., 2014), but this kind of research failed to show how the upgrading in regional industrial value chain (IVC) help Beijing-Tianjin-Hebei's manufacturing industry to build NVC and break the GVC low-end lock.

This paper attempts to examine the internal mechanism of regional industrial upgrading and regional economic cooperation from the perspective of NVC, take the traditional manufacturing industry of Beijing, Tianjin and Hebei as the research object, and analyze the influencing factors of Beijing-Tianjin-Hebei manufacturing industry from NVC perspective. On the basis of this, this paper analyzes the transmission mechanism of industrial upgrading, and finally puts forward the theoretical basis for the development of industrial policy and the development path of enterprises in Beijing, Tianjin and Hebei through the construction of the theoretical model and specific upgrading path of Beijing-Tianjin-Hebei manufacturing industry. 


\section{Restrictive Factors of Manufacturing Industry Upgrading in Beijing-Tianjin-Hebei Based on NVC}

The national value chain (NVC) is in close contact with the global value chain (GVC). Constructing the NVC is based on the embedding in the GVC and the realization of industrial development, so the docking with the GVC will be a very important model choice to the constructing of NVC. In the process of connecting with the GVC, we must pay special attention to the function of NVC model in the industrial upgrading of Beijing-Tianjin-Hebei in the GVC, for the sake of breaking the domestic enterprises' status "captured" and "locked" in the low-end in the GVC. This is one of the key whether NVC can promote the regional industry to upgrade or not.

The choice of the NVC model should not only consider the industrial upgrading of economically developed areas in the region, but also must consider the industrial upgrading of economically undeveloped areas in the region, that is, by selecting a reasonable domestic value chain model, so that the underdeveloped areas can achieve effective interaction and linkages with the developed industries in the region, and avoid the "resource curse" development path that relies on resources, energy, raw materials and labor in this process, so as to realize the coordinated development in all areas of the region.

Based on the background of NVC, this paper analyzed the mechanism of industrial upgrading from different perspectives, such as market demand, trade scale, environmental regulation, resource investment, talent flow, industrial structure, institutional arrangement and so on. As shown in figure 4.1.

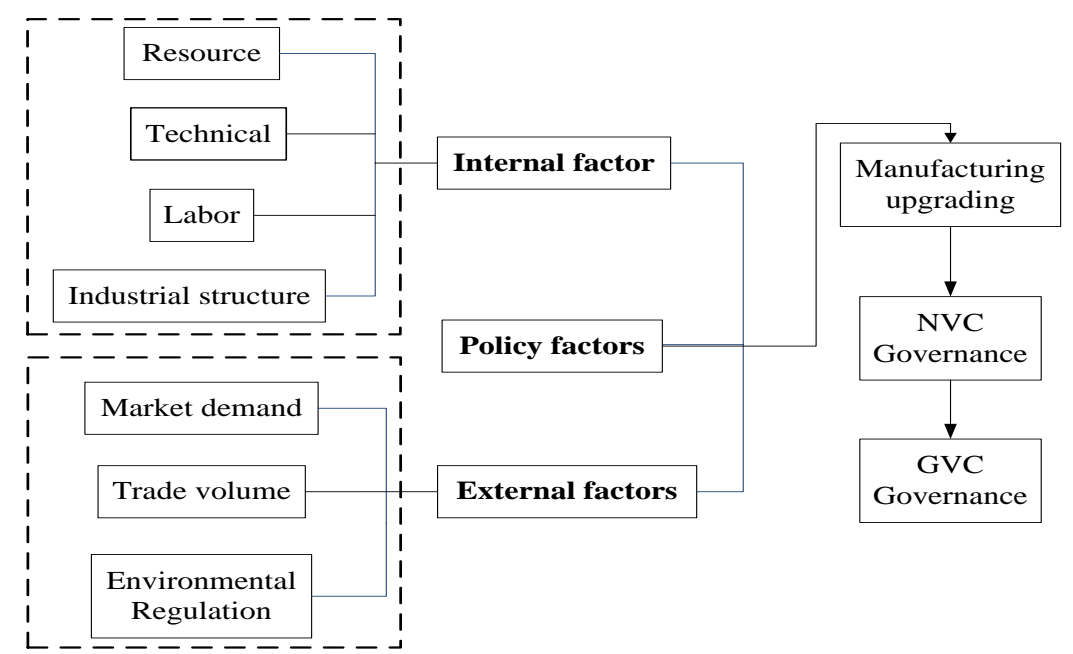

Fig.4.1 Factors affecting the upgrading of manufacturing industry under NVC

From the perspective of the internal factors, although Beijing has a strong policy advantage and outstanding scientific and technological factors, Tianjin has a convenient location advantages and a strong manufacturing base and Hebei has a wealth of labor factors and low land rent, but the process of transformation and upgrading of manufacturing industry in these areas are not smooth. Wei Ran and Li Guoliang considered that the development of Beijing, Tianjin and Hebei was originally unbalanced, which leads to the resources within the region is mainly from Hebei to the one-way flow of Beijing and Tianjin, the "polarization" phenomenon is obvious, which exacerbate the vicious spiral between Beijing and Tianjin and Hebei, eventually leading to industry in the three areas docking difficult and hard to form a supporting industry chain. Meanwhile, the industrial structure adjustment of the three places did not break through the administrative boundaries in the process of upgrading in value chain, and the regional areas were more focused on local interests and lacked the overall concept of regional cooperation. Although Beijing had established the idea of industrial restructuring very early, and some low-end industries have been transferred to Hebei, but because of the cooperation with Tianjin's industry is not enough, making the Beijing-Tianjin-Hebei regional development and industrial upgrading is not coordinated. In addition, the convergence of 
internal industry transfer in Beijing-Tianjin-Hebei is not strong, on the one hand, the transfer of the old industry is not enough in Beijing and Tianjin; on the other hand, the proportion of general manufacturing is large and the service industry is developing slowly in Hebei and its surrounding areas, which caused the industrial undertaking capacity is limited. Finally, due to the convergence of industrial structure, in the process of upgrading in the value chain, the objectives of regional industrial structure adjustment focus on immediate interests, making the problem of industrial structure convergence intensified, the regional competition is more than the reality of cooperation, restricting the advanced of regional industrial structure.

From the perspective of the external factors, although the total economic output of the Beijing-Tianjin-Hebei is larger than the Pearl River Delta region, but the growth rate is lower than the Yangtze River Delta region, and in the view of fiscal revenue, the Yangtze River Delta region is four times as much as the Beijing-Tianjin-Hebei region. From the view of total import and export trade, the Beijing-Tianjin-Hebei region is not only lower than the Pearl River Delta region, but also has a big gap with the Yangtze River Delta region.

The root cause of this result is that a unified regional market does not formed in the Beijing-Tianjin-Hebei, and the current situation of market segmentation has hindered the movement of labor, capital and other factors in the region and the formation of a unified consumer goods market, for example, Of the security considerations and the traditional strong government, weak market situation in Beijing, Tianjin and Hebei, resulting in the region's capital market lack of vitality and motivation, affecting the independent capital need of enterprises in the real economy; Beijing and Tianjin have strict household registration restrictions, affecting the free movement of this region's labor force; The scarcity and monopoly of land resources in urban and rural areas affect the development of rural land market and the value-added of wealth; for some innovative areas, too much government's participation has weakened the innovation and creativity of the enterprises; Administrative division and the performance appraisal of economic growth strengthen the local protectionism, forming the region's artificial market segmentation. In addition, there are differences in the opening up and attracting foreign investment in Beijing-Tianjin-Hebei, Beijing and Tianjin have attracted more foreign investment, so that the gap between the three Beijing and Tianjin to attract more foreign investment, so that the gap between the three areas gradually widening (Cui Dongchu and Song Zhijie, 2012), These are all going against the construction of regional value chain and the upgrading of manufacturing.

In addition to the market demand and trade scale, the serious environmental problems has also restricted the transformation and upgrading of the manufacturing in Beijing-Tianjin-Hebei. In recent years, the 'haze' and 'PM2.5' are quite frequently apparent in these areas, water pollution and shortage continue to intensify, which has a significant correlation with the backward industrial structure in Beijing-Tianjin-Hebei region. Hebei is the important area in energy, steel, heavy chemical industry, the coordinated development of Beijing-Tianjin-Hebei requires not only transferring and governing some of the heavy chemical industry, but also requires its upgrading. Under the huge pressure of environmental regulation, coupled with the lack of power to upgrade the industries in Hebei, which in turn restricting the central cities' industrial upgrading.

It is concluded that resource input, human input, technical factors, industrial structure are endogenous factors, market demand, trade scale, environmental regulation as exogenous factors, institutional factors are closely related to endogenous factors and exogenous factors, and interact with each other to promote the upgrading of manufacturing industry.

\section{References}

[1] Feldman M P, Audretsch D B. Innovation in Cities: Science Based Diversity, Specialization and Localized Competition[J].European Economic Review,1999 (2),p409 429

[2] Glaeser E L, Kallal H D, Scheinkman, J A, et al. Growth in Cites[J].The Journal of Political Economy, 1992 (6),p1126 1152

[3] Jacobs J. The Economy of Cities [M].New York: Vintage Books USA,1969.

[4] Marshall A. Principles of Economics [M]. London: Macmillan and Co. Ltd.,1890. 
[5] Luiza Bazan, Aizbeth Navas Alemán. The underground revolution in the Sinos Valley: acomparison of upgrading in global and national value chains. in Hubert Schmitz, ed Local Enterprises in the Global Economy: Issues of Governance and Upgrading[C].in Hubert Schmitz, Edited.2004,p110 139. 